\title{
Early Recovery from Anosmia and Ageusia of COVID-19 by Practice of Slow Breathing of Pal's Pranayama Schedule: A Brief Communication
}

\author{
Uttareshwar Pachegaonkar ${ }^{1, *}$, Duraisamy Rathinam Rajesh ${ }^{2}$
}

\section{Uttareshwar \\ Pachegaonkar ${ }^{1, *}$, Duraisamy Rathinam Rajesh $^{2}$}

\section{'Sri Aurobindo Society, Puducherry,} INDIA.

${ }^{2}$ Department of Forensic Medicine, Indira Gandhi Medical College and Research Institute, Puducherry, INDIA.

\section{*Correspondence}

Dr. Uttareshwar Pachegaonkar Senior Homeopathy and Alternative Medicine Physician, Sri Aurobindo Society, Puducherry, INDIA.

Phone: +919443602666

Email: dr.uttareshwar@gmail.com

\section{History}

- Submission Date: 28-08-2020

- Review completed: 10-09-2020

- Accepted Date: 25-09-2020.

DOI : 10.5530/ijcep.2020.7.3.28

Article Available online

http://www.ijcep.org

\section{Copyright}

(C) 2020 Phcog.Net. This is an openaccess article distributed under the terms of the Creative Commons Attribution 4.0 International license.

\begin{abstract}
Though 80\% of corona virus disease 2019 (COVID-19) patients recover without much medical intervention, the process of recovery is delayed in few patients with continuation of myalgia, headache, weakness and loss of taste and smell sensations. Reports indicate improvement of cardiorespiratory, neuromuscular and sensory functions following practice of yoga, especially slow pranayamas. Therefore, a case study was conducted to assess if practice of slow breathing exercise of Pal's pranayama schedule can facilitate recovery from anosmia and ageusia in COVID-19 illness.

Key words: COVID-19, Anosmia, Ageusia, Slow breathing exercise, Pal's pranayama.
\end{abstract}

\section{INTRODUCTION}

Though $80 \%$ of corona virus disease 2019 (COVID-19) patients recover without much medical intervention, the recovery period in few of them is prolonged due to persistence of myalgia, weakness, headache and stress-related problems. ${ }^{[1]}$ Recently it is reported that the loss of smell (anosmia) or taste (ageusia) is among the most common and persistent symptoms of COVID-19 in patients with mildly symptomatic disease, which may take four to six weeks from the onset, for complete resolution or improvement of these symptoms. ${ }^{[2]}$ To date, there is no evidence of any effective treatment for COVID-19, especially for the sensory problems in the post-recovery period though antiviral drugs are being used. ${ }^{[3]}$ There are several ongoing clinical trials of both western and traditional medicines for development of new therapies and vaccines for treatment of COVID-19.

Practice of yoga has been reported to improve sensory functions in various clinical disorders. [4] Especially, asanas and pranayama's have been reported to improve brain activities including cognitive functions and sensory perceptions. ${ }^{[5]}$ Among yoga techniques, the practice of pranayamas (controlled breathings) has been reported to promote autonomic, neurosensory and respiratory functions. ${ }^{[6]}$ Among different types of pranayama's, the chandranadi pranayama (left-nostril breathing) and anulom-vilom pranayama (alternatenostril breathing) have been demonstrated to have maximum beneficial effects on autonomic cardiorespiratory functions. ${ }^{[7,8]}$ Pal's pranayama, a structured slow breathing exercise that comprises of both chandranadi and anulom-vilom pranayama's has been documented to be effective in preventing ventricular tachycardia by improving cardiac autonomic vagal (parasympathetic) modulation. [9] We proposed that Pal's pranayama would also improve sensory perception of smell and taste as nasopharyngeal (mucosa of nose, oral cavity, oropharynx and nasopharynx) functions are controlled by parasympathetic nerves. Therefore, the present case study was conducted to assess if practice of Pal's pranayama schedule can facilitate recovery from anosmia and ageusia in a COVID-19 patient.

\section{METHODS}

Approval of Research Advisory Committee and Human Ethics Committee of Sri Aurobindo Society, Puducherry, India, an international organization approved by Government of India for integral research in alternative medicines, was obtained to conduct the study. The written informed consent was obtained from the patient.

\section{THE CLINICAL REPORT}

A 45 years old female had fever, dry cough and headache and was detected to be COVID-19 positive. She was admitted on $12^{\text {th }}$ August 2020, to COVID ward of Indira Gandhi Medical College and Research Institute, a COVID-designated hospital of Government of Puducherry, India. She was given tab. Paracetamol (500mg one b.d.) and Vitamin B complex and she became afebrile in two days. From second day of her admission, she developed loss of smell sensation followed by taste sensation and she
Cite this article: Pachegaonkar U, Rajesh DR. Early Recovery from Anosmia and Ageusia of COVID-19 by Practice of Slow Breathing of Pal's Pranayama Schedule: A Brief Communication. Int J Clin Exp Physiol. 2020;7(3):119-21. 
had mild headache with the sensation of nasal obstruction. Though she was given xylometazoline nasal drops and did vapor inhalation and warm saline gargling, the problems continued. As she was afebrile for one week, she was discharged from hospital on $20^{\text {th }}$ August 2020. She was advised 7 days home quarantine.

Inspite of warm saline gargling and vapor inhalation, there was no recovery from loss of smell and taste sensation and the patient was very apprehensive for not being able to enjoy routine life that includes eating and smelling, due to these sensory perception deficits. The patient was much disturbed for not able to smell and recognize the taste food. She came to know from her close relations that an asana-pranayama schedule is helping in faster recovery from the problems of COVID-19 disease. The yoga expert was contacted and she was advised to practice the slow breathing exercise of Pal's Pranayama schedule. ${ }^{[9]}$ The details of the technique and procedure were sent to her through her WhatsApp (details given below) and that she immediately learnt and started practicing the pranayama schedule. She was relieved from the intermittent headache and mild nasal obstruction and there was about $50 \%$ improvement in smell sensation within one day of pranayama practice. In next two days, she could fully perceive the sensation of taste and smell. She became completely alright in four days of practicing pranayama. She continued to practice the pranayama programme. Her one week of quarantine period became eventless and she was happy to recover from these problems.

\section{The Pal's Pranayama Schedule}

The patients practiced the slow breathing exercise of Pal's pranayama schedule as described below. ${ }^{[9]}$

- $\quad$ Sitting comfortably in nasika mudra, gently close the right-nostril by the thumb and inhale deeply in the left-nostril while counting $1-5$ in mind and then slowly exhale in the same nostril counting $1-10$ in mind or as much as possible.

- $\quad$ Repeat the same process of breathing in left-nostril.

- Then, inhale deeply in the left nostril counting 1-5 in mind and close the left nostril by the index finger and exhale slowly in the right nostril counting 1-10 in mind and then inhale deeply in right nostril counting 1-5 in mind and close the right nostril by thumb and exhale slowly in the left nostril counting 1-10 in mind, or as much as possible.

- This completes one pranayama cycle, which has two rounds of the left-nostril (Chandranadi) breathing, followed by one round of alternate nostril (Anulom-Vilom) breathing.

- In this slow pranayama, expand chest optimally during each act of inspiration and relax the body and mind as much as possible during each act of expiration.

- Practice about 20 cycles of this pranayama in one schedule.

The pranayama schedule was practiced by the patient once in the morning between 6.00 AM to 6.30 AM, once before lunch and once in the evening between 5.30 PM to 6.00 PM, each session lasting about 20 $\min$.

\section{DISCUSSION}

The major objectives of treatment of COVID patients are to facilitate recovery, relieve apprehension and stress and prevent the development of respiratory illness, by strengthening the muscles of thoracic cage, abdominal wall and facilitate the functioning of respiratory apparatus and to promote sensory-neural functions. Practice of pranayamic breathing has been shown to be effective in improving cardio-pulmonary, autonomic and sensory-neural functions. ${ }^{[10]}$ In Pal's pranayama schedule, which is a combination of chandranadi (left-nostril) with anulomvilom (alternate-nostril) breathings, the duration of expiration is more prolonged to further strengthen the cardiopulmonary functions. ${ }^{[9]}$ As slow nostril breathing has been reported to promote vagal tone while strengthening the sympathovagal balance, ${ }^{[11]}$ the increased duration of expiration in this slow pranayamic breathing might have further potentiated the vagal tone and improved oxygen uptake and oxygenation of tissues of the body including brain that improves sensory perception and cognitive functions ${ }^{[5]}$ In addition, the slow pranayama improves the functioning of respiratory passages, improves the blood flow to the nasal and oropharyngeal mucus membranes and the functions of sensory neurons, ${ }^{[10]}$ and therefore is expected to improve the perception of smell and taste.

Studies have revealed that both ACE2 and TMPRSS2 genes targeted by SARS-CoV-2 virus to enter the cells especially in respiratory tract, are expressed by cells in the olfactory epithelium, the specialized tissue in the roof of the nasal cavity responsible for odour detection. ${ }^{[12]}$ It is further observed that two specific cells named sustentacular cells, which wrap around sensory neurons and provide structural and metabolic support to neurons and basal cells, which act as stem cells that regenerate the olfactory epithelium, express both ACE2 and TMPRSS 2 genes. Thus, it has been proposed that the loss of smell sensation could be due to the damage to these mucosal epithelial cells in COVID-19. ${ }^{[13]}$

Also, it has been observed that SARS-CoV-2 does not directly infect neurons but may instead interfere with brain or neurological functions by affecting vascular cells in the neural tissues. ${ }^{[12]}$ It has been noted that neurons in the olfactory bulb do not express ACE2 and TMPRSS2 genes, though they are present in blood vessel cells, particularly pericytes of the bulb, which are involved in blood pressure regulation, bloodbrain barrier maintenance and inflammatory responses. ${ }^{[13]}$ Thus, we hypothesize that Pal's pranayama might have improved the sensation of smell by improving the functions of sustentacular cells and basal cells in the olfactory epithelium by increasing blood flow to the nasal epithelium and to the olfactory bulb. A similar mechanism might have operated in improving the taste sensation.

Pal's pranayama as observed in the present study has facilitated the recovery from anosmia and ageusia. Nevertheless, with the practice of this slow pranayama schedule, the body-mind of the subject get relaxed, in addition to improvement of cardiorespiratory and sensorineural functions. It is reported that fear, nervousness, anxiety disorders and sleep disorders are common in COVID-19 patients, in addition to malaise and weakness. ${ }^{[14]}$ As reported recently the COVID-19 patients continue to suffer from anosmia and ageusia for a prolonged period, which further psychologically disturbs them. ${ }^{[2]}$ Therefore, as observed in this case study, the pranayama practice could not only facilitate the recovery from ageusia and anosmia of COVID-19 patients, but also would improve their psychophysical health, especially in the recovery period. However, studies should be conducted in a larger sample size to assess the efficacy of Pal's pranayama in overall patient population of COVID-19. The limitation of the study is that the report is based on the qualitative assessment of smell and taste based on the expression of patient's perception. The sensorineural function tests and histological alterations in oral-nasal mucosal epithelial cells or taste buds to quantify the perception of smell and taste before and after the pranayama intervention have not been done.

\section{ACKNOWLEDGEMENT}

Authors acknowledge the support provided by Shri Vijay Poddar, Chief Executive of Sri Aurobindo Society in the conduct of this study.

\section{Funding}

No funding was utilized in this project. 


\section{CONFLICT OF INTEREST}

Authors declare they have no conflict of interest.

\section{ABBREVIATIONS}

COVID-19: Corona Virus Disease 2019; ACE2: Angiotensin Converting Enzyme 2; TMPRSS2: Transmembrane Protease Serine 2.

\section{REFERENCES}

1. Li LQ, Huang T, Wang YQ, Wang ZP, Liang Y, Huang TB, et al. 2019 novel coronavirus patients' clinical characteristics, discharge rate and fatality rate of meta-analysis. J Med Virol. 2020;92(6):577-83.

2. Boscolo-Rizzo P, Borsetto D, Fabbris D, Spinato G, Frezza D, Menegaldo A, et al. Evolution of altered sense of smell or taste in patients with mildly symptomatic COVID-19. JAMA Otolaryngol Head Neck Surg. 2020;146(8):729-32.

3. Pascarella G, Strumia A, Piliego C, Bruno F, Buono RD, Costa F, et al. COVID-19 diagnosis and management: A comprehensive review (Review). J Intern Med. 2020;288:192-206.

4. Campbell M, Martin S. Exploring yoga as a sensory based intervention for children with sensory processing difficulties: A systematic literature review. MOJ Yoga Physical Ther. 2017;2(4):101-8.

5. Kyizom T, Singh S, Singh KP, Tandon OP, Kumar R. Effect of pranayama and yogaasana on cognitive brain functions in type 2 diabetes-P3 event related evoked potential (ERP). Indian J Med Res. 2010;131(5):636-40.
6. Pal GK, Velkumary SM. Effect of short-term practice of breathing exercises on autonomic functions in normal human volunteers. Ind $\mathrm{J}$ Med Res. 2004;120(2):115-21.

7. Bal BS. Effect of anulom vilom and bhastrika pranayama on the vital capacity and maximal ventilatory volume. J Phys Educ Sport Manag. 2010;1(1):11e5.

8. Singh S, Gaurav V, Parkash V. Effects of a 6-week nadi-shodhana pranayama training on cardio-pulmonary parameters. J Phys Educ Sport Manag. 2010;2(4):44e7.

9. Pal GK. Disappearance of ventricular ectopics following 15-day practice of Pal's pranayama schedule. Int J Clin Exp Physiol. 2018;5(2):105-7.

10. Pal GK, Pal P, Nivedita N. Physiology of yoga. In: Comprehensive textbook of medical physiology, $2^{\text {nd }}$ Edition, 2019. Jaypee Publications. New Delhi. 2019;1359-76

11. Pal GK, Agarwal A, Karthik S, Pal P, Nanda N. Slow yogic breathing through right and left nostril influences sympathovagal balance, heart rate variability and cardiovascular risks in young adults. North Am J Med Sci. 2014;6(3):145-51.

12. Bilinska K, Jakubowska P, Bartheld CSV, Butowt R. Expression of the SARSCoV-2 entry proteins, ACE2 and TMPRSS2, in cells of the olfactory epithelium: Identification of cell types and trends with age. ACS Chem Neurosci. 2020;11(11):1555-62.

13. Brann DH, Tsukahara T, Weinreb C, Lipovsek M, DenBerge KV, Gong B, et al. Non-neuronal expression of SARS-CoV-2 entry genes in the olfactory system suggests mechanisms underlying COVID-19-associated anosmia. Sci Adv. 2020;6(31):eabc5801.

14. Balachandar V, Mahalaxmi I, Subramaniam M, Kaavya J, Kumar NS, Gracy L. Follow-up studies in COVID-19 recovered patients: Is it mandatory?. Sci Total Environ. 2020;729:139.

Cite this article: Pachegaonkar U, Rajesh DR. Early Recovery from Anosmia and Ageusia of COVID-19 by Practice of Slow Breathing of Pal's Pranayama Schedule: A Brief Communication. Int J Clin Exp Physiol. 2020;7(3):119-21. 